\title{
HUBUNGAN TINGKAT PENGETAHUAN IBU HAMIL TRIMESTER III TENTANG TANDA-TANDA BAHAYA KEHAMILAN DENGAN KEPATUHAN KUNJUNGAN ANC DI WILAYAH KERJA PUSKESMAS KARANG PULE
}

\author{
Aulia Amini ${ }^{*}$, Ana Pujianti Harahap* \\ ${ }^{1 *}$ Kebidanan, Universitas Muhammadiyah Mataram, auliaamini1406@gmail.com
}

INFO ARTIKEL

Riwayat Artikel:

Diterima: 24-04-2017

Disetujui: 01-07-2017

\section{A. LATAR BELAKANG}

Kehamilan merupakan saat yang menyenangkan dan dinanti-nanti, tetapi juga dapat menjadi kegelisahan dan keprihatinan. Didalam kehamilan diperlukan pengawasan atau pemeriksaan secara teratur yang lebih dikenal dengan Ante Natal Care (ANC). ANC merupakan bagian terpenting dari kehamilan. Dengan memeriksakan secara teratur diharapkan dapat

\begin{abstract}
Abstrak: ANC dapat mendeteksi adanya tanda-tanda bahaya selama kehamilan untuk mengurangi faktor risiko yang terjadi. Tujuan untuk mengetahui hubungan tingkat pengetahuan ibu hamil trimester III tentang tanda-tanda bahaya kehamilan dengan kepatuhan kunjungan ANC. Penelitian ini menggunakan metode observasional analitik. Populasinya adalah seluruh ibu hamil Trimester III yang berdomisili diwilayah kerja Puskesmas Karang Pule sebanyak 50 orang. Teknik sampling dengan total Sampling, Analisis dengan uji chi square. Hasil penelitan dari 50 responden diketahui sebagian besar memiliki Tingkat pengetahuan baik dan cukup sebanyak 43 orang (86\%) dan yang paling sedikit berada pada tingkat pengetahuan kurang sebanyak 7 orang (14\%) tingkat kepatuhan responden yang berkategori tidak patuh sebanyak 28 orang (56\%) dan yang patuh yaitu sebanyak 16 orang (32\%) dengan tingkat pengetahuan cukup dan sebagian kecil responden yang berkategori tidak patuh sebanyak 3 orang (6\%) dengan tingkat pengetahuan baik serta hasil dari analisis menggunakan uji Chi Square pada tingkat kepatuhan 0,05, diperoleh hasil 0,970 atau probabilitas diatas $0,05(0,970>0,05)$, maka $\mathrm{H}_{\circ}$ diterima atau tidak terdapat hubungan yang signifikan antara tingkat pengetahuan ibu hamil trimester III tentang tandatanda bahaya kehamilan dengan kepatuhan kunjungan ANC di wilayah kerja Puskesmas Karang Pule.
\end{abstract}

ABSTRAK

\begin{abstract}
ANC can detect any signs of danger during pregnancy to reduce the risk factors that occur. Objective to know the relationship of the level of knowledge of pregnant women trimester III of pregnancy danger signs with compliance visits ANC. this research use analytic observational methods. Its population is a whole Trimester pregnant mothers residing region III work Clinics Coral Pule as much as 50 people. The sampling technique with total Sampling, analysis by chi square test. The results of a study of 50 respondents are known to have the level of knowledge of good and quite as many as 43 people (86\%) and at least be at the level of knowledge is lacking as many as 7 people (14\%) the compliance level respondents wayward categories as many as 28 people (56\%) and the wayward i.e. as many as 16 people (32\%) with enough knowledge level and a small portion of the respondent's wayward categories by as much as 3 people (6\%) with a good level of knowledge as well as the results of the analysis using the Chi Square test on the compliance levels of 0.05 , obtained results above 0.05 probability or $0.970(0,970>0.05)$, then there is no Ho accepted or significant relationships between levels the III trimester of pregnant women's knowledge about the danger signs of pregnancy with the ANC visit compliance in the area of employment primary health care Karang Pule.
\end{abstract}

mendeteksi lebih dini keadaan-keadaan yang mengandung resiko kehamilan dan atau persalinan, baik bagi ibu maupun janin (Prawirohaidjo, 2006).

Pemeriksaan kehamilan terutama K4 merupakan salah satu bentuk kepatuhan masyarakat dalam menjaga dan meningkatkan derajat kesehatan. Kepatuhan merupakan tingkat perilaku pasien sesuai dengan ketentuan yamg diberikan oleh petugas kesehatan (Niven, 2008). 
Cakupan kunjungan ibu hamil di Propinsi NTB K1 tahun 2013 sebesar 98\% capaiannya 93,59\%, menurun 5\%dibanding realisasi tahun 2012 yaitu sebesar 98,53\%. Jumlah ibu hamil yang mendapat pelayanan antenatal K1 masih kurang dari yang ditargetkan sasaran ibu hamil di tahun 2013, sedangkan cakupan kunjungan ibu hamil K4 sebesar 89,86\% (target 98\%) tahun 2012, sebesar 91,85\% (target 95\%) tahun 2011, belum tercapainya cakupan ini disebabkan karena masih terdapat ibu hamil kontak pertama dengan Nakes (K1) diatas umur kehamilan 12 minggu, sehingga dimungkinkan akan terjadi drop out pada kunjungan K4. (Dikes Provinsi NTB, 2013).

Berdasarkan data Dikes Kota Mataram tahun 2013 data di Karang Pule merupakan Puskesmas terendah ke-tiga untuk cakupan kunjungan ANC. Cakupan kunjungan ibu hamil di Puskesmas Karang Pule K1 tahun 2013 yaitu sebesar 97,79\% menurun 3\% dibanding tahun 2011 yaitu sebesar 94,35\%, tahun 2012 menurun 2\% dibanding tahun 2011 yaitu sebesar 92,13\%, tahun 2013 sebesar 89,85\% menurun 3\% dibanding tahun 2012. Sedangkan cakupan kunjungan ibu hamil K4 sebesar 93,56\% tahun 2010, sebesar 91,43\% tahun 2011, sebesar 89,54\% tahun 2012,dan sebesar 86,56\% tahun 2013 (Dikes Kota Mataram, 2013).

Dari hasi Studi pendahuluan yang dilakukan pada 10 orang ibu hamil trimester III di Puskesmas Karang Pule dengan Tingkat Pengetahuan Tentang TandaTanda Bahaya Dalam Kehamilan di simpulkan bahwa 7 dari 10 ibu hamil trimester III (7\%) dengan pengetahuan kurang, 2 dari 10 ibu hamil trimester III (2\%) yang berpengetahuan baik serta 1 dari $10 \mathrm{ibu}$ hamil trimester III (1\%) dengan pengetahuan cukup.

Berdasarkan latar belakang tersebut, peneliti tertarik untuk melakukan penelitian tentang Hubungan Tingkat Pengetahuan Ibu Hamil Tentang Tanda Bahaya Kehamilan Dengan Kepatuhan Kunjungan ANC di Puskesmas Karang Pule Kota Mataram.

\section{B. METODE PENELITIAN}

Penelitian ini menggunakan metode penelitian observasional analitik Penelitian ini bertujuan untuk mengetahui hubungan tingkat pengetahuan ibu hamil trisemester III tentang tanda-tanda bahaya kehamilan dengan kepatuhan kunjungan ANC di wilayah kerja Puskesmas Karang Pule, serta mengidentifikasi beberapa variabel yaitu variabel independen yang meliputi pengetahuan ibu hamil Trimester III tentang tanda-tanda bahaya kehamilan, serta variabel dependen yakni kepatuhan kunjungan ANC.

Penelitian ini menggunakan desain cross-sectional dimana semua data yang merupakan variabel penelitian dikumpulkan dalam satu saat tertentu (waktu yang bersamaan) dan hanya diobservasi sekali saja (Notoatmodjo, 2010). Tempat Penelitian ini dilaksanakan di wilayah kerja Puskesmas Karang Pule Kota Mataram.
Populasi pada penelitian ini adalah seluruh ibu hamil Trimester III yang berdomisili di wilayah kerja Puskesmas Karang Pule dengan jumlah 50 orang. Sampel Sampel dalam penelitian ini adalah teknik total sampling yaitu total sampel sama dengan total populasi yaitu sebanyak 50 orang. Pada penelitian ini teknik pengumpulan data yang digunakan adalah jenis data primer dan data sekunder serta tekhnik observasi langsung kepada responden yang bersedia sesuai dengan kreteria. Instrumen penelitian dilakukan uji Validitas dan uji Reliabilitas.

Analisa data yang digunakan dalam penelitian ini adalah dengan menggunakan analisa univariat dan bivariat. Penulis menggunakan Skala data ordinalnominal. Untuk menguji hipotesis dalam penelitian ini menggunakan uji Chi Square dengan alat bantu SPSS16.o. (Santjaka, 2008).

\section{HASIL DAN PEMBAHASAN}

Berdasarkan hasil penelitian yang telah dilakukan oleh peneliti berdasarkan tingkat pengetahuan responden dapat diketahui bahwa sebagian besar responden memiliki tingkat pengetahuan yang cukup sebanyak 28 orang (56\%) dan yang paling sedikit berada pada tingkat pengetahuan kurang sebanyak 7 orang (14\%).

Jadi dapat dilihat bahwa masih adanya responden yang memiliki pengetahuan yang kurang dan lebih banyak yang memiliki pengetahuan cukup tentang tanda bahaya kehamilan dikarenakan karena mayoritas ibu hamil berpendidikan dasar (SD-SMP) 54\%, dimana tingkat pendidikan sangat mempengaruhi tingkat pengetahuam seseorang.

Responden juga mayoritas pekerjaan tidak bekerja (IRT) $64 \%$ sehingga kurang mendapatkan informasi dari lingkungannya. Hal ini menunjukkan bahwa penyampaian informasi tentang tanda bahaya kehamilan masih kurang sehingga ibu hamil tidak mengerti apa manfaat melakukan ANC dan dampak tidak melakukan kunjungan ANC secara teratur.

Tingkat kepatuhan responden dapat diketahui bahwa sebagian besar responden yang berkategori tidak patuh sebanyak 28 orang (56\%) di bandingkan dengan yang berkategori patuh yaitu sebanyak 22 orang (44\%).

Jadi dapat dilihat bahwa responden tidak patuh melakukan kunjungan ANC karena tidak mengerti tentangmanfaat dari melakukan kunjungan ANC dan dampak tidak melakukanANC. Sehingga perlu diberikan promosi kesehatan ataupun penyuluhan kepadasetiap ibu hamil tentang manfaat melakukan ANC dan dampak tidak melakukan ANC yang dapat menambah pengetahuan ibu hamil sehingga dapat mengubah perilaku ibu hamil dalam melakukan ANC menjadi lebih patuh.

Hubungan antara pengetahuan ibu hamil trimester III tentang tanda-tanda bahaya kehamilan dengan kepatuhan kunjungan ANC responden dapat diketahui 
bahwa sebagian besar responden yang berkategori tidak patuh yaitu sebanyak 16 orang (32\%) dengan tingkat pengetahuan cukup dan sebagian kecil responden yang berkategori patuh sebanyak 3 orang (6\%) dengan tingkat pengetahuan kurang.

Walaupun dari hasil analisa hubungan tingkat pengetahuan ibu hamil trimester III tentang tanda-tanda bahaya kehamilan dengan kepatuhan kunjungan ANC di wilayah kerja puskesmas karang pule tahun 2015 menggunakan uji Chi Square pada tingkat kepatuhan $\alpha=$ 0,05, diperoleh nilai probalitas adalah 0,970 $(0,970>0,05)$, maka Ho diterima atau tidak terdapat hubungan yang signifikan antara tingkat pengetahuan ibu hamil trimester III tentang tanda-tanda bahaya kehamilan dengan kepatuhan kunjungan ANC di wilayah kerja puskesmas karang pule tahun 2014.

\section{SIMPULAN DAN SARAN}

Simpulan penelitian ini dari 50 responden dapat diketahui bahwa sebagian besar responden memiliki tingkat pengetahuan yang cukup sebanyak 28 orang (56\%) dan yang paling sedikit berada pada tingkat pengetahuan kurang sebanyak 7 orang (14\%). Dari 50 responden dapat diketahui bahwa sebagian sebagian besar memiliki tingkat pengetahuan baik dan cukup sebanyak 43 orang (86\%) dan yang paling sedikit berada pada tingkat pengetahuan kurang sebanyak 7 orang (14\%)tingkat kepatuhan responden yang berkategori tidak patuh sebanyak 28 orang (56\%) dan yang tidak patuh yaitu sebanyak 16 orang (32\%) dengan tingkat pengetahuan cukup dan sebagian kecil responden yang berkategori patuh sebanyak 3 orang (6\%) dengan tingkat pengetahuan kurang.

Dari hasil analisa hubungan tingkat pengetahuan ibu hamil trimester III tentang tanda-tanda bahaya kehamilan dengan kepatuhan kunjungan ANC di wilayah kerja puskesmas karang pule tahun 2015 menggunakan uji Chi Square pada tingkat kepatuhana $=0,05$, diperoleh nilai probalitas adalah $0,970(0,970>0,05)$, maka $\mathrm{H}_{\mathrm{o}}$ diterima atau tidak terdapat hubungan yang signifikan antara tingkat pengetahuan ibu hamil trimester III tentang tanda-tanda bahaya kehamilan dengan kepatuhan kunjungan ANC di wilayah kerja puskesmas karang pule tahun 2014.

Saran dalam penelitian ini diharapkan hasil penelitian ini dapat menambah informasi dan pengetahuan serta menambah wawasan khususnya mengenai pengetahuan ibu hamil tentang tandatanda bahaya kehamilan dan kepatuhan dalam kunjungan ANC. Kepada petugas kesehatan untuk meningkatkan pelayanan dalam memberikan konseling maupun health education kepada masyarakat khususnya ibu hamil. Disarankan kepada masyarakat untuk menambah wawasan dan informasi tentang pentingnya ANC bagi ibu hamil dan meningkatkan pengetahuan ibu hamil tentang tanda-tanda bahaya kehamilan agar ibu hamil dapat mengetahui lebih dini komplikasi yang terjadi pada ibu dan kehamilannya.

\section{DAFTAR RUJUKAN}

[1] Arikunto, S. (2006) Prosedur Penelitian Suatu Pendekatan Praktik. Rineka Cipta: Jakarta.

[2] Dikes Kota Mataram. (2013) Cakupan Pelayanan Antenatal. Mataram : NTB

[3] Dikes Provinsi NTB. (2013) Cakupan Pelayanan Antenatal. http: //www. dikes. ntbprov. go. id

[4] Notoatmodjo, Soekidjo. 2010. Metodologi Penelitian Kesehatan. Rineka Cipta: Jakarta.

[5] Niven. 2008. Psikologi kesehatan pengantar untuk perawat dan profesionalisme. Jakarta:EGC.

[6] Prawirohadjo, S. (2006) Ilmu Kebidanan. BP-SP: Jakarta.

[7] Sudariah. (2007) Kepatuhan Melakukan KunjunganAntenatal Care.http://www.docstoc.com Online,diakses. 